\title{
O PASSEIO: A LITERATURA COMO POTÊNCIA PARA A EXPERIÊNCIA ESTÉTICA
}

\author{
Leomar Peruzzo ${ }^{1}$ \\ Carla Carvalho ${ }^{2}$
}

\section{Resumo}

Este artigo objetiva discutir os conceitos em torno da experiência estética e as potências de um livro literário destinado ao público infantil de autor local. O suporte para a discussão teórica está em Duarte Jr. (1981, 2001, 2012), Larrosa (2016), Carvalho (2012), Neitzel e Bridon (2012), Carvalho (2008), Deleuze e Guattari (1992). Adota-se como foco de investigação a experiência estética provocada pela literatura e suas reverberações mediante a leitura fruitiva no olhar de quatro sujeitos de idades diferenciadas, presentes no cotidiano dos pesquisadores. As questões apontadas pelas experiências mostraram que a potência artística da sequência de imagens e textos metafóricos são os principais elementos provocadores da experiência estética.

Palavras-chave: Arte. Experiência estética. Literatura infantil. Potência. Metáfora da vida.

\section{O PASSEIO: LITERATURE AS A POWER FOR THE AESTHETIC EXPERIENCE}

\begin{abstract}
This paper aims to discuss the concepts in relation to the aesthetic experience and the potency of a literary book intended for children written by a local author. The theoretical discussion is based on Duarte Jr. (1981, 2001, 2012), Larrosa (2016), Carvalho (2012), Neitzel and Bridon (2012), Carvalho (2008), Deleuze and Guattari (1992). We adopted as focus of investigation the aesthetic experience provoked by literature and its reverberations through the fruitive reading in the point of view of four subjects of different ages, present in the daily life of the researchers. The issues raised by the experiences showed that the artistic potency of the sequence of images and metaphorical texts are the main provocative elements of the aesthetic experience.
\end{abstract}

Keywords: Art. Aesthetic experience. Children's literature. Potency. Metaphor of life.

Figura 1. Páginas iniciais do livro

\footnotetext{
${ }^{1}$ Universidade Federal do Paraná (UFPR), Curitiba - Paraná - Brasil. Doutorando em Educação pelo Programa de Pós-Graduação em Educação da Universidade Federal do Paraná (UFPR). É professor de Arte da rede municipal de educação de Blumenau. ORCID <https://orcid.org/0000-0001-5322-142X>. E-mail: leomarperuzzo@hotmail.com.

${ }^{2}$ Universidade Regional de Blumenau (FURB), Blumenau - Santa Catarina - Brasil. Doutora em Educação pela Universidade Federal do Paraná (UFPR). professora no Programa de Pós-Graduação em Educação e na graduação em Cursos de Formação de Professores e Design na Universidade Regional de Blumenau (FURB). ORCID <https://orcid.org/0000-0002-1402-7920>. E-mail: ca_carvalho@icloud.com.
} 


\section{Linguagens - Revista de Letras, Artes e Comunicação - ISSN 1981- 9943 \\ Blumenau, v. 13, n. 3, p. 412-429, set./dez. 2019 \\ DOI: http://dx.doi.org/10.7867/1981-9943.2019v13n3p412-429}

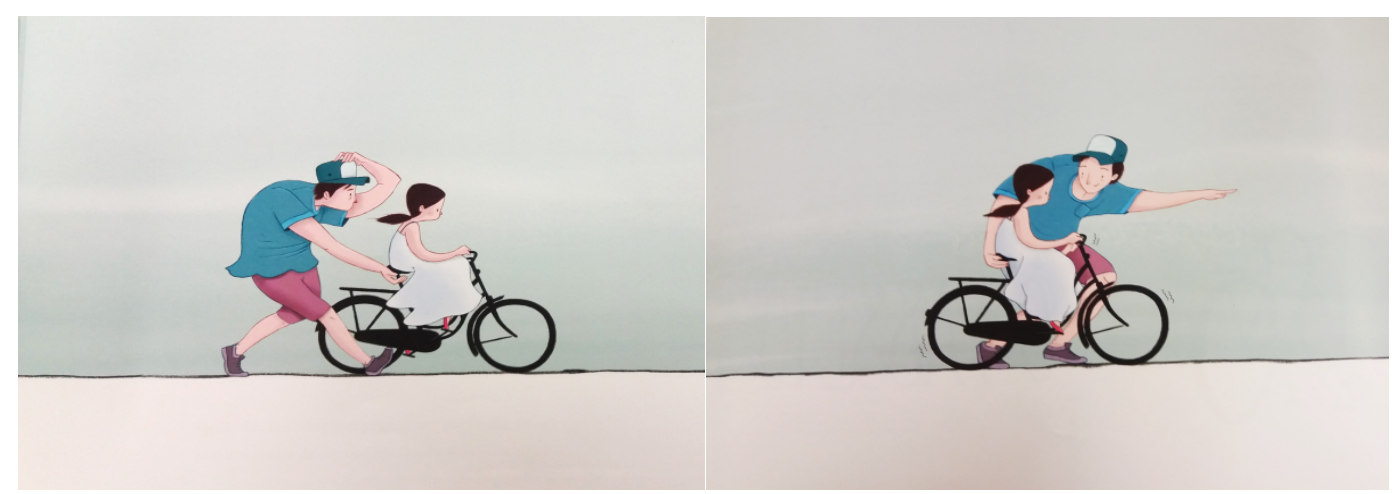

Fonte: Extraídas de O passeio, Lugones e Rampazo (2017, p. 1-2).

Iniciamos nosso passeio com as primeiras imagens do livro que nos provocou a escrever este artigo. $\mathrm{O}$ encontro com esse livro deu-se no dia de seu lançamento (verão de 2017). Ao percorrermos nossos olhares por sua narrativa, percebemos que seu conteúdo, sua estética, suas provocações visuais e textuais, nos instigaram à fruição. Assim, convidamos você, leitor, a vagar pelos entrelaçamentos deste texto e, se possível, buscar nele as sensações e as emoções próprias da experiência estética que provocaram alguns leitores.

\subsection{APROXIMAÇÕES ESTÉTICAS}

Aquele dia quando o pai perguntou: "Preparada filha?". Mal tive tempo de responder e já saí a toda velocidade. (LUGONES; RAMPAZO, 2017, p. 4)

Essas primeiras palavras do livro $O$ passeio $^{3}$, que propomos como epígrafe, é um convite a aventurarmo-nos pelas tramas deste texto. Pensar em um livro é pensar em uma viagem, em um passeio como metáfora de um percurso apreciativo de uma obra, possível de ser lida com múltiplas interpretações. Afinal, se uma obra de arte é plurissignificativa, portanto, ao apreciá-la ou realizar uma leitura, ou várias leituras, estas nos afetam em diversas intensidades. Aí está a justificativa da escolha dessa obra - nós, autores deste artigo, afetamonos com ela ao ponto de tecer este estudo.

Vivemos, nos últimos anos, nos dedicando a compreender como se dão as relações entre as pessoas e as obras de arte, sejam elas visuais, literárias, musicais, teatrais, da dança, entre outras linguagens. Nesse percurso, percebemos singularidades entre as maneiras que os sujeitos se afetam com as obras de arte e, ao mesmo tempo, se conectam com os elementos

\footnotetext{
${ }^{3}$ Este é o primeiro livro de Lugones. Recebeu no ano de seu lançamento o Selo Distinção Cátedra 10 de Leitura da UNESCO, em 2017; Seleção Catálogo da Fundação Nacional do Livro Infantil e Juvenil (FNLIJ) para a Feira de Bolonha 2018.
} 


\section{Linguagens - Revista de Letras, Artes e Comunicação - ISSN 1981- 9943 \\ Blumenau, v. 13, n. 3, p. 412-429, set./dez. 2019 \\ DOI: http://dx.doi.org/10.7867/1981-9943.2019v13n3p412-429}

presentes nos contextos em que vivem. Assim, fizemos a conexão com a educação estética e os processos de mediação cultural na relação com as obras de arte e os contextos de educação formal e não formal. Os percursos permitiram perceber que podemos passear pela vida ou, simplesmente, passar pelos acontecimentos sem que nada nos afete.

As questões relacionadas à educação e à experiência estética são assuntos que geram intensas discussões no Grupo de Pesquisa em Arte e Estética na Educação do Programa de Pós-Graduação em Educação da Universidade Regional de Blumenau (FURB) e no Grupo de Pesquisa Cultura, Escola e Educação Criadora da Universidade do Vale do Itajaí (UNIVALI) ${ }^{4}$. Essas discussões instigam-nos a investigar as relações estabelecidas entre o olhar do observador e o objeto artístico. Nessa direção, consiste como propósito deste estudo promover espaços reflexivos para analisar uma obra literária destinada para o público infantil $1^{5}$, como objeto propositor de experiências estéticas.

Ao adotarmos como objeto de análise a obra literária de Pablo Lugones e Alexandre Rampazo, intitulada $O$ passeio, de 2017, nós a percebemos como potente objeto estético gerador dos dados analisados neste breve estudo. Partindo desses pressupostos, o que nos inquieta e move-nos ao encontro da ação reflexiva é a tentativa de compreender como um livro de literatura possui potência ${ }^{6}$ para desencadear experiências estéticas. Assim, questionamo-nos: Quais as potências que o livro de literatura possui para desencadear experiências estéticas?

Supondo certa intencionalidade dos meios tecnológicos, midiáticos e informadores (smartphones, televisores, internet e rádio), permitimo-nos afirmar que eles promovem certo atrofiamento das sensibilidades humanas. Nessa era da informação, diante do condicionamento de corpos, mentes e atitudes por meio do arsenal imagético, ou seja, a imagem veiculada velozmente, em redes virtuais, plataformas publicitárias e aparelhos eletrônicos, abortam as possibilidades de vivermos uma intensa experiência estética. Assim, com os argumentos de Larrosa (2016), podemos complementar que: "Nunca se passaram tantas coisas, mas a experiência é cada vez mais rara. Em primeiro lugar pelo excesso de informação" (LARROSA, 2016, p. 18).

\footnotetext{
${ }^{4}$ Os dois Grupos de Pesquisa possuem parcerias, aproximando pesquisadores das duas instituições com foco nos temas Educação Estética e Mediação Cultural.

${ }^{5}$ Acreditamos que a obra literária não se restringe a um público em específico, mas a quem está disponível para a apreciação. Na ficha catalográfica, ela está indicada como literatura infantil, literatura infanto-juvenil, mas essa obra é aberta a toda e qualquer idade, como discutimos neste artigo.

${ }^{6} \mathrm{O}$ termo "potência" está conectado à noção de força ativa, causalidade eficácia, poder de agir. Conceito disponível em: <https://sites.google.com/view/sbgdicionariodefilosofia/pot\%C3\%AAncia $>$. Acesso em: 10 maio 2018.
} 


\section{Linguagens - Revista de Letras, Artes e Comunicação - ISSN 1981- 9943 \\ Blumenau, v. 13, n. 3, p. 412-429, set./dez. 2019 \\ DOI: http://dx.doi.org/10.7867/1981-9943.2019v13n3p412-429}

De acordo com o filósofo, a informação funciona como um bloqueador da experiência, agindo como uma espécie de "antiexperiência". Desse modo, percebemos que a função da informação nos contextos contemporâneos é enfatizar o estar informado e "[...] toda a retórica destinada a constituir-nos como sujeitos informantes e informados [...] não faz outra coisa que cancelar nossas possibilidades de experiência" (LARROSA, 2016, p. 18-19).

Nesse sentido, de acordo com Duarte Jr. (2001), vivemos em certa crise dos sentidos que está relacionada “[...] a uma maneira de se compreender o mundo e de sobre ele agir, maneira que se veio identificando como tributária dessa forma específica de atuação da razão humana: a forma instrumental, calculante, tecnicista, de se pensar o real" (DUARTE JR., 2001, p. 69).

Essa maneira contemporânea de perceber e agir em coletividade também apresenta características definidas pelos "[...] simulacros corporais veiculados pela mídia, os quais vão servindo de modelo aos ávidos consumidores, uma série gigantesca de produtos é vendida a todo aquele que pretenda atingir tal ideal" (DUARTE JR., 2001, p. 116). Nesse contexto, as experiências corporais e sensíveis são subjugadas aos simulacros imagéticos, não restando espaço para possibilidades de construção de sentidos, submetendo qualquer vivência do corpo, ao consumismo de bens e serviços especializados. "Para se manter a forma física através de exercícios há que se consumir calçados e roupas especiais, bem como frequentar academias que dispõem de máquinas e aparelhos sofisticados” (DUARTE JR., 2001, p. 116).

A complexidade da vida contemporânea resulta de uma imbricada trama de "[...] fatores físicos, metabólicos, sensíveis, emocionais, ambientais, sociais e culturais", condicionada a um processo crescente de abstração, provocando a obstrução progressiva da manifestação dos saberes sensíveis que o próprio corpo naturalmente possui (DUARTE JR., 2001, p. 61). Diante desse cenário, em que a informação, seja pela imagem, seja por outro signo de comunicação, é fator de controle comportamental, denuncia uma crise da experiência.

Para Larrosa (2016, p. 25), “[...] é incapaz de experiência aquele a quem nada the passa, a quem nada lhe acontece, a quem nada lhe sucede, a quem nada o toca, nada lhe chega, nada o afeta, a quem nada o ameaça, a quem nada ocorre". Ainda, segundo o autor, a experiência é tida como algo que acontece e que desloca o observador, que transforma em outro quem experimenta, que modifica o pensamento e a ação na relação com tal acontecimento.

Se a experiência, segundo Larrosa (2016), implica experimentar algo, uma relação sensível, podemos conectar esse conceito ao de experiência estética, foco deste estudo. Para 


\section{Linguagens - Revista de Letras, Artes e Comunicação - ISSN 1981- 9943 \\ Blumenau, v. 13, n. 3, p. 412-429, set./dez. 2019 \\ DOI: http://dx.doi.org/10.7867/1981-9943.2019v13n3p412-429}

Duarte Jr. (2012), a experiência estética ocorre em relação ao objeto artístico e, nesse contato, coloca-se em jogo as elaborações simbólicas que desenvolvemos com o mundo ao longo da existência. "A obra cria em mim uma experiência de 'como se': frente a ela é como se eu estivesse vivenciando a situação que ela me propõe, com todas as maravilhas, dores e prazeres que isto me desperta” (DUARTE JR., 2012, p. 364).

A literatura compreendida como objeto de arte pode proporcionar encontros com dimensões da sensibilidade e imaginação humana, em um jogo de afetos inerente à toda experiência literária, que, segundo Diniz (2017, p. 478), consiste em “[...] um modo de nos aproximarmos das obras por meio de sensações físicas e emoções".

Direcionamos nossos olhares sensíveis para também buscar compreender a relação da experiência estética com o desenvolvimento de capacidades sensíveis, na reflexão em torno da crise dos sentidos, que, segundo Duarte Jr. (2001), necessita receber foco reflexivo a fim de estimular a educação da sensibilidade como capacidade inteligível.

Ao avançarmos neste estudo, apresentaremos fundamentos para nossos conceitos centrais e tentaremos desenvolver diálogos significativos, com o intuito de promover a experiência do pensamento sensível por meio da palavra. Também apresentaremos a análise da obra literária citada anteriormente, apontando os principais aspectos de sua estrutura, em que os "olhares" dos apreciadores serão foco de reflexão, para, então, tecermos as considerações em torno do percurso de estudo.

\section{2}

\section{A EXPERIÊNCIA ESTÉTICA EM LITERATURA}

\section{A obra de arte é um ser de sensação, e nada mais: ela existe em si. \\ (DELEUZE; GUATTARI, 1992, p. 213)}

Para iniciarmos um percurso reflexivo que possa desencadear em experiências de pensamento, convocamos as vozes dos autores que, de uma maneira ou de outra, estimulam a potência do diálogo, na trama de significados, ao ponto de provocar "tremores", como registra Larrosa (2016). Intencionamos, neste trecho do estudo, estabelecer conexões com as bases teóricas, de forma que, abrindo brechas, o leitor possa elaborar reflexões em torno da experiência estética.

Segundo Larrosa (2016), a base para o exercício da experiência do pensamento está no diálogo. Para que isso ocorra, é preciso a troca eficiente de palavras, e que estas, em suas significações, possam potencializar a produção de sentidos, a criação de realidades, agindo como “[...] potentes mecanismos de subjetivação" (LARROSA, 2016, p. 16). O autor ainda 


\section{Linguagens - Revista de Letras, Artes e Comunicação - ISSN 1981- 9943 \\ Blumenau, v. 13, n. 3, p. 412-429, set./dez. 2019 \\ DOI: http://dx.doi.org/10.7867/1981-9943.2019v13n3p412-429}

afirma acreditar no poder das palavras e em sua própria força, pois elas estruturam nossos pensamentos. "As palavras determinam nosso pensamento porque não pensamos com pensamentos, mas com palavras, não pensamos a partir de uma suposta genialidade ou inteligência, mas a partir de nossas palavras" (LARROSA, 2016, p. 16).

Nesse sentido, o jogo de palavras é o recurso que utilizamos também para dar sentido ao que pensamos e às experiências que vivemos. Por isso, pensar está conectado ao que elaboramos a partir do que nos ocorre, aos sentidos que atribuímos a partir das palavras. "E, portanto, também tem a ver com as palavras o modo como nos colocamos diante de nós mesmos, diante dos outros e diante do mundo em que vivemos. E o modo como agimos em relação a tudo isso" (LARROSA, 2016, p. 17).

Podemos, então, definir o pensamento e aquilo que nos acontece como dinâmicas que estão intimamente conectadas às experiências e aos conhecimentos delas elaborados por meio da palavra. Assim, o que faz diferença em nosso percurso de aprendizagens é "[...] como damos sentido ao que somos e ao que nos acontece, de como correlacionamos as palavras e as coisas, de como nomeamos o que vemos ou o que sentimos e de como vemos ou sentimos o que nomeamos" (LARROSA, 2016, p. 17).

Se as palavras possuem a potência de modificar nossas conexões mentais e o pensamento, podemos questionar-nos qual a potência da imagem e como elas podem reverberar em nossas elaborações intelectuais e sensíveis. Dessa forma, é inevitável que tais questionamentos venham à tona, bem como pensar a força das imagens nas relações entre o pensamento e o sentimento, até tornar-se palavra encarnada (LARROSA, 2016). O olhar é a chave da relação imagética que desempenha papel crucial quando se trata da experiência de pensamento e das possíveis elaborações a partir da relação com diversos estímulos, e, nesse caso, analisaremos um livro de literatura que baseia sua narrativa fundamentalmente em imagens.

Nesse contexto, Larrosa (2016) propõe pensarmos em torno do conceito de experiência, importante para este estudo. Esta parece estar envolvida em uma nebulosa definição entre aquilo que experimentamos e aquilo que elaboramos a partir dela. Etimologicamente, a palavra "experiência" possui origem no latim experiri (provar, experimentar). Para Larrosa (2016), a experiência estabelece uma relação com algo experimentado, provado. “O radical é periri, que se encontra também em periculum, perigo. A raiz indo-européia é per, com a qual se relaciona antes de tudo a idéia de travessia, e secundariamente a ideia de prova" (LARROSA, 2016, p. 26). 


\title{
Linguagens - Revista de Letras, Artes e Comunicação - ISSN 1981- 9943 \\ Blumenau, v. 13, n. 3, p. 412-429, set./dez. 2019 \\ DOI: http://dx.doi.org/10.7867/1981-9943.2019v13n3p412-429
}

De acordo com o autor, as definições para o termo experiência estão conectadas àquilo que nos acontece e que causa certa instabilidade na ordem interna de pensamento, permitindo elaborações denominadas "saberes da experiência". Segundo Larrosa (2016):

\begin{abstract}
Se a experiência é o que nos acontece e se o saber da experiência tem a ver com a elaboração do sentido ou do sem-sentido do que nos acontece, trata-se de um saber finito, ligado à existência de um indivíduo ou de uma comunidade humana particular; ou, de um modo ainda mais explícito, trata-se de um saber que revela ao homem concreto e singular, entendido individual ou coletivamente, o sentido ou o sem-sentido de sua própria existência, de sua própria finitude. Por isso, o saber da experiência é um saber particular, subjetivo, relativo, contingente, pessoal. Se a experiência não é o que acontece, mas o que nos acontece, duas pessoas, ainda que enfrentem o mesmo acontecimento, não fazem a mesma experiência. (LARROSA, 2016, p. 32).
\end{abstract}

Esse excerto acena o teor subjetivo da experiência e sugere a dimensão dos saberes que advém dela. Talvez os fatores que definem a subjetividade e a originalidade de cada experiência e os saberes que dela surgem estariam intimamente relacionados aos contextos experienciados por cada sujeito. É “[...] a experiência é o que me transforma, me constitui, me faz como sou, marca minha maneira do ser, configura minha pessoa e minha personalidade. [...] a experiência é a que forma, a que nos faz como somos, a que transforma o que somos e o que converte em outra coisa" (LARROSA, 2016, p. 48).

Diante desses aspectos, percebemos que a subjetividade é característica comum em toda experiência devido a variáveis encontradas em cada modo de perceber e elaborar o que nos acontece. Os sentidos e os significados são individuais. Por isso,

[...] a experiência é sempre de alguém, subjetiva, e sempre daqui e de agora, contextual, finita, provisória, sensível, mortal, de carne e osso como a própria vida. A experiência tem algo da opacidade, da obscuridade e da confusão da vida, algo da desordem e da indecisão da vida. (LARROSA, 2016. p. 40).

Nesse sentido, em certo ponto da argumentação, Larrosa (2016) aponta para aquilo que nos acontece com tal intensidade que causa instabilidades internas associadas à ideia de tremores, vibrações, ressonâncias. Seria “[...] algo que nos faz pensar, algo que nos faz sofrer, gozar, ou algo que luta pela expressão, e que às vezes, algumas vezes, quando cai em mãos de alguém capaz de dar forma a esse tremor, então, somente então, se converte em canto" (LARROSA, 2016, p. 10).

O transformar a experiência subjetiva em "canto" faz a arte ser única. Ela possui sentido e si própria, portanto "[...] o sentido que ela exprime existe nela e apenas nela. Quando a contemplo, ela evoca em mim determinados sentimentos intraduzíveis, indizíveis e 


\section{Linguagens - Revista de Letras, Artes e Comunicação - ISSN 1981- 9943 \\ Blumenau, v. 13, n. 3, p. 412-429, set./dez. 2019 \\ DOI: http://dx.doi.org/10.7867/1981-9943.2019v13n3p412-429}

inexprimíveis, a não ser através dela própria” (DUARTE JR., 1981, p. 76). Esse teor simbólico está relacionado à determinada condição em si própria, e a obra apresenta um ponto de vista da vitalidade, emoção, da realidade subjetiva do artista. Assim, o artista utiliza-se de signos, símbolos convencionados, sinais, recursos determinados para representar aquilo que quer comunicar (DUARTE JR., 1981).

Considerando a obra artística um produto da ação humana ao expressar certa subjetividade emocional traduzida na composição de elementos artísticos e suas relações, ela apresenta, de uma forma ou de outra, certa qualidade artística e estética. A arte permite experimentar, mesmo que pareça simulação, sensações distintas, que Duarte Jr. (2012) afirma serem

[...] acontecimentos e experiências de vida de outras pessoas, de outras latitudes, de outras realidades, ou mesmo da minha e que me eram desconhecidas. Portanto, também a arte é capaz de nos abrir os olhos para maravilhas e espantos inusitados, a partir dos quais sempre se pode depois, evidentemente, refletir e elaborar conceitualmente. (DUARTE JR., 2012, p. 364).

Contudo, para que os códigos da arte sejam desvendados, o autor apresenta a necessidade de "aprendizagens" em relação aos próprios códigos da arte. Para ele, a "experiência estética" só pode ocorrer com o contato frequente com a própria obra de arte, bem como nessa relação de desenvolver a aprendizagem dos códigos da arte e a educação da sensibilidade emocional e do olhar (DUARTE JR., 2012).

Dessa forma, constantemente surgem questionamentos em torno de qual seria a função da arte nos contextos atuais. Se a arte reúne a expressão da subjetividade humana por meio da forma, a principal função da arte está nela mesma como objeto de estímulo às sensações, permitindo a contemplação geradora de experiências estéticas. Por meio da arte, podemos estimular o que Duarte Jr. (1981) chama de "experiência interior”, em uma relação com a vida que as formas artísticas podem proporcionar. Segundo o autor:

\footnotetext{
Situando-se a meio caminho entre a vida vivida e a abstração conceitual, as formas artísticas visam a significar esse nosso contato carnal com a realidade, e a sua apreensão opera-se bem mais através de nossa sensibilidade do que via o intelecto. A arte não estabelece verdades gerais, conceituais, nem pretende discorrer sobre classes de eventos e fenômenos. Antes, busca apresentar situações humanas particulares nas quais esta ou aquela forma de estar no mundo surgem simbolizadas e intensificadas perante nós. (DUARTE JR., 2001, p. 23).
}

O autor instiga-nos a pensar a arte como um meio para intensificar, o que ele chama de "contato carnal com a realidade", em uma tentativa de trazer à discussão as possibilidades de alargamento da percepção e de sermos afetados por essas percepções. Como se a carne 


\section{Linguagens - Revista de Letras, Artes e Comunicação - ISSN 1981- 9943 \\ Blumenau, v. 13, n. 3, p. 412-429, set./dez. 2019 \\ DOI: http://dx.doi.org/10.7867/1981-9943.2019v13n3p412-429}

(materialidade sensível do corpo) fosse meio fundamental para estabelecermos relações íntimas com objetos estéticos. Esses objetos estéticos, neste estudo, delimitamos aqueles trabalhos de arte que possuem potência para desencadear experiências estéticas.

Essas experiências estéticas, por sua vez, compreendem as abstrações, as elaborações sensíveis que resultam delas. Elas são responsáveis por causarem sensações que, talvez, possam ser intraduzíveis em palavras, mas que suas reverberações ocorrem “[...] primordialmente no corpo, colocando em funcionamento processos biológicos que têm a ver com isto que denominamos sentimento" (DUARTE JR., 2001, p. 136).

Duarte Jr. (2001) provoca-nos ainda a pensar em como as dinâmicas do sentimento ocorrem no corpo e como elas podem ser dimensões relevantes na construção de saberes definidos como "saberes sensíveis". Estes por sua vez são elaborações que o indivíduo é capaz de fazer diante das relações estabelecidas com os contextos de aprendizagem ou obras de arte. Nesse sentido, a capacidade de sentir é definida como sendo estesia, como a sensibilidade perceptiva ao mundo e aos fenômenos. Estesia está intimamente conectada à significação da palavra "estética". Originariamente, os dois termos derivam do grego “aisthesis", representando a habilidade sensível e perceptiva do indivíduo em elaborar aquilo que experimenta, aquilo que lhe acontece ao ser exposto aos estímulos dos contextos culturais (DUARTE JR., 2001).

O autor ainda destaca que o conceito "estética" possui diversificadas definições conectadas à "experiência da beleza", ao objeto de arte e ao termo "estesia", como [...] nossa prontidão para apreender os sinais emitidos pelas coisas e por nós mesmos" (DUARTE JR., 2001, p. 136-137). Essa prontidão em perceber os sinais contidos em diversas fontes está relacionada ao corpo que se apresenta como lugar das sensações. $O$ corpo na contemporaneidade está sujeito a condicionamentos que inibem a sensibilidade, a percepção e negam as dimensões humanas, gerando certa "anestesia" ou incapacidade de sentir, bem como de experienciar o que lhe ocorre (DUARTE JR., 2001).

O conceito de fruição está relacionado ao universo artístico. Assim, ao ser considerado como ação conectada à obra literária, pode potencializar experiências estéticas. Para Barthes (1996), o texto de prazer diferencia-se do texto de fruição. O primeiro é "[...] aquele que contenta, enche, dá euforia; aquele que vem da cultura, não rompe com ela, está ligado a uma prática confortável da leitura" (BARTHES, 1996, p. 22). Esse sentido aproxima-se do que podemos definir como mero entretenimento. E o segundo, o texto de fruição, 


\section{Linguagens - Revista de Letras, Artes e Comunicação - ISSN 1981- 9943 \\ Blumenau, v. 13, n. 3, p. 412-429, set./dez. 2019 \\ DOI: http://dx.doi.org/10.7867/1981-9943.2019v13n3p412-429}

[...] põe em estado de perda, aquele que desconforta (talvez até um certo enfado), faz vacilar as bases históricas, culturais, psicológicas, do leitor, a consistência de seus gostos, de seus valores e de suas lembranças, faz entrar em crise sua relação com a linguagem. (BARTHES, 1996, p. 22).

Com esses argumentos, é possível afirmar que a fruição consiste no momento em que o observador se relaciona com um objeto estético, ou obra de arte, ao ponto de causar esse "desconforto", que desestrutura existencialmente as bases da linguagem, abrindo espaços para a contemplação.

Ao dialogarmos com esses filósofos, ousamos complementar as discussões, trazendo vozes de pesquisadoras do estado de Santa Catarina que investigam a literatura com uma abordagem fruitiva. De acordo com Carvalho (2012), a literatura fruitiva consiste em um fenômeno estético, que abre caminhos para compreender os universos da própria literatura e também permite “[...] a apreensão de uma nova visão de mundo, ampliando sua consciência da realidade. A arte, nessa perspectiva, nunca é movimento alienante porque coloca o sujeito em um momento de fruição em contato com a realidade representada" (CARVALHO, 2012, p. 64).

Essas evidências permitem afirmar que o leitor possui papel importante diante do objeto literário, também definido como objeto estético por sua potência de estímulo às percepções. Carvalho (2012) defende que o leitor reconstrói a obra e possui

[...] papel ativo no momento em que se sente seduzido pelo livro, nesse caso, aquilo que ele vê na obra respaldado pelas marcas semânticas do texto, torna-se um produto de significações e ele, o leitor, um produtor. Particularmente, o leitor estabelece, no silêncio da sua leitura, dadas compreensões que fogem às mãos do autor da obra, $o$ silêncio permeia a construção da obra e o olhar do leitor, que pode vir ao encontro dos objetivos do autor, mas pode, ainda, fugir em definitivo. (CARVALHO, 2012 p. 63).

Os encontros com a literatura podem ser os mais diversos e inusitados e em espaços que vão além dos escolares, onde comumente a literatura encontra espaço fértil. Já a literatura destinada a crianças também encontra espaço para apreciação nos ambientes escolares, porém depende dos estímulos e das ações mediadoras para que as experiências estéticas sejam potencializadas. É comum percebermos intensas apropriações de recursos imagéticos para compor as obras literárias, configurando certa miscigenação de linguagens.

Para Neitzel e Bridon (2012), uma obra literária pode ser constituída de imagens que, com sua plasticidade, amplia "[...] o significado da palavra poética. Vimos afirmando que a justaposição de várias linguagens é, sem dúvida, uma produção cultural rica que tende a levar o leitor a reescrever por meio da leitura um texto mais poroso, mais prenhe de sentidos" 


\section{Linguagens - Revista de Letras, Artes e Comunicação - ISSN 1981- 9943 \\ Blumenau, v. 13, n. 3, p. 412-429, set./dez. 2019 \\ DOI: http://dx.doi.org/10.7867/1981-9943.2019v13n3p412-429}

(NEITZEL; BRIDON, 2012, p. 74). As pesquisadoras trazem à tona a importância da literatura para o desenvolvimento do pensamento e da percepção sensível do mundo. É a experiência estética na literatura que permite ampliarmos os modos de pensar, de opinarmos e, fundamentalmente, de agirmos com alteridade, com efetiva abertura ao outro e à diversidade. Dessa forma é

[...] que aceitamos diferentes pensamentos, percebemos o outro como um ser pensante, porque também nos tornamos pensantes. A imaginação é uma competência que pode ser estimulada por diversas vias, mas delas pelo exercício da leitura de obras literárias, e influencia não só nossa capacidade comunicativa e criativa, mas também o desenvolvimento de nossa sensibilidade e percepção. (NEITZEL; BRIDON, 2012, p. 73).

Em consonância com os argumentos apresentados em torno das funções da obra literária para os mais diversos públicos, principalmente para o público infantil e adolescente, podemos retomar a voz de Carvalho (2012). Ela define que a literatura encerra em si e nos processos fruitivos importante função de apreensão de significados e de desenvolvimento da linguagem. Dessa forma, a literatura, na condição de "[...] objeto estético, atrelado à concepção da literatura fruitiva, [...] envolve o leitor e o carrega para o espaço novo e do imaginário, propiciando a criança ler não somente livros, mas o mundo em que vive e as relações que estabelece" (CARVALHO, 2012, p. 68).

A obra literária como produção artística relaciona-se diretamente à subjetividade humana, propõe deslocamentos em contextos em que está inserida. Dessa forma, “[...] a obra, enquanto 'ser' objetivo, possui 'vida própria', dialoga com o criador e com o fruidor num processo de constante criação que proporciona ao indivíduo consciência e apreensão do mundo" (CARVALHO, 2008, p. 58).

É com essa dimensão de objeto estético que nos aproximamos da obra literária a ser desvendada. O livro escolhido para este estudo destina-se ao público infantil, porém a potência de suas imagens metafóricas ultrapassa os limites estabelecidos pelas recomendações de idade para adentrar à dimensão subjetiva do ser humano. Compreender como se dá esse fenômeno e buscar respostas para nossa questão central é que se faz necessário analisar os depoimentos de "Olhares" aguçados para a narrativa imagética proposta pelos autores do livro.

\section{O PASSEIO: MÚLTIPLOS OLHARES À OBRA LITERÁRIA}




\section{Linguagens - Revista de Letras, Artes e Comunicação - ISSN 1981- 9943 \\ Blumenau, v. 13, n. 3, p. 412-429, set./dez. 2019 \\ DOI: http://dx.doi.org/10.7867/1981-9943.2019v13n3p412-429}

Os olhares que trazemos referem-se aos sujeitos que, ao estabeleceram relação fruitiva com a obra literária, expuseram suas impressões de forma espontânea. Nosso contato inicial com a obra provocou-nos a ponto de levarmos a obra aos nossos contextos pessoais e profissionais. Nesse percurso, optamos por um movimento no qual a pesquisa se aliasse ao cotidiano, pois observamos, em nosso movimento, o olhar de pesquisador curioso para cada pessoa que encontrava com o livro. Decidimos realizar o registro e, nesse sentido, sistematizamos uma proposta metodológica que tivesse a configuração de um encontro encontro com uma obra de arte - e, por meio dele, faríamos o registro da fala ou das falas que surgissem dessa experiência. Nosso critério de escolha foi: uma pessoa disposta a ler, independentemente da idade. Tivemos conosco quatro leitores selecionados para este artigo. Os sujeitos que participaram são de distintas idades - 9, 30, 45 e 54 anos (uma criança e três adultos). As três pessoas adultas possuem formações acadêmicas distintas, exercem profissões distintas e apreciaram o livro em momentos distintos.

Oferecemos a obra para ser apreciada a leitores de diversas idades e diferentes níveis de formação. Não lemos para essas pessoas. Cada uma pegou e leu o livro que oferecemos. Nós ficamos ao lado, somente olhando. Posteriormente, registramos as falas manifestadas após a apreciação do livro sem questionamentos ou intervenções de qualquer ordem que pudesse interferir no depoimento. O que pedimos foi que expusessem a sua percepção em torno da obra literária apreciada.

O passeio, de autoria de Lugones e Rampazo (2017), apresenta bases metafóricas que juntamente a imagens compõem a potente narrativa. Os textos verbais são sucintos, exercendo função pontual, mas secundária na trama sequencial de imagens. Estas configuram o principal recurso que compõe a narrativa.

Figura 2. Capa do livro de literatura

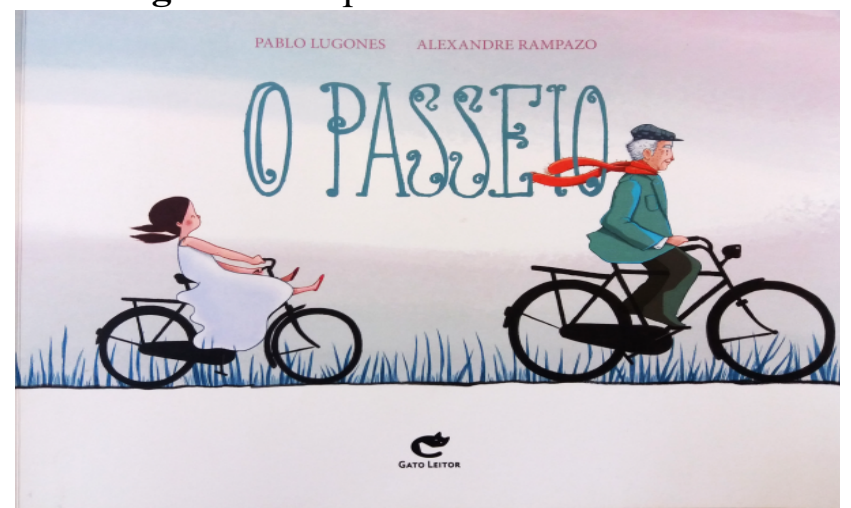

Fonte: Extraída de O passeio, Lugones e Rampazo (2017, n.p.). 


\section{Linguagens - Revista de Letras, Artes e Comunicação - ISSN 1981- 9943 \\ Blumenau, v. 13, n. 3, p. 412-429, set./dez. 2019 \\ DOI: http://dx.doi.org/10.7867/1981-9943.2019v13n3p412-429}

De acordo com Carvalho (2008), na literatura, a imagem estabelece diálogos com o texto verbal, “[...] na tentativa de coadunarem diálogos que intuem complementar ou, ainda, ampliar a experiência estética do leitor. Neste sentido, imagem e texto se tornam elementos essenciais para a relação do leitor com aquela obra" (CARVALHO, 2008, p. 113-114). Ao analisarmos os depoimentos e estabelecermos relações com a obra literária em foco neste estudo, percebemos múltiplas reações físicas como arrepios, sensações, lembranças de infância relatadas por distintos olhares.

Analisamos depoimentos em busca de evidências da experiência estética e suas reverberações. A partir desses depoimentos, percebemos que ela possibilita a reflexão em torno da função de uma obra literária como potência para a educação da sensibilidade e da percepção humana. Esses aspectos que se dão no corpo, em uma ideia de dimensão sensorial, material, intelectual, não são fragmentados. Um corpo que mesmo submetido a inúmeros mecanismos de controle, sujeitado, atrofiado sensivelmente, ainda é capaz de abrir brechas ao que é natural no ser humano: sua capacidade de sentir. Esses aspectos da sensação ficam evidentes nos depoimentos a seguir, gerados logo após a leitura do livro. O olhar um ${ }^{7}$ declarou sentir arrepios, sensação intensa que tomou o corpo inteiro e, em seguida, apontou uma reflexão que remeteu a afetos familiares. No trecho a seguir, podemos perceber esses aspectos:

Olhar um: "Nossa, estou arrepiada 'mana'. Arrepiada inteira. Pensei nos meus pais ainda vivos e que terei eles por pouco tempo talvez. Meu pai nunca brincou com a gente, e pouco abraçou a gente. Ele era antigo e achava que demonstrar amor iria acabar com a autoridade dele".

Esse excerto claramente apresenta intensa conexão com memórias familiares relacionadas aos pais e aos afetos que tais memórias evocaram. No olhar um, a leitora já passou dos 50 anos de idade, seus pais têm mais de 80 anos. Isso a fez, por mais de uma vez, repetir a diferença e o tempo de vida que seu pai ainda pode ter. Para Diniz (2017, p. 482), as sensações e as emoções estão agrupadas ao conceito de afetos que “[...] podem ser despertados por, e irradiar em torno de, experiências vivas que extrapolam o perceptual rumo à linguagem ou ao pensamento reflexivo".

O que podemos perceber nas palavras do trecho anterior é a nítida reação emocional na relação com a narrativa imagética do livro. O arrepiar-se está na dimensão do corpo, do afeto, que despertou memórias e deslocamentos para o campo da reflexão em torno da condição humana e as relações familiares. Esse fato aponta para uma possível experiência

\footnotetext{
${ }^{7}$ Adotamos o termo "olhar" para nomear os participantes deste estudo e garantir o seu anonimato.
} 


\section{Linguagens - Revista de Letras, Artes e Comunicação - ISSN 1981- 9943 \\ Blumenau, v. 13, n. 3, p. 412-429, set./dez. 2019 \\ DOI: http://dx.doi.org/10.7867/1981-9943.2019v13n3p412-429}

estética que mobilizou dimensões sensíveis que surgem no corpo, assumindo o que podemos definir como sentimento e reflexão (DUARTE JR., 2001).

O olhar dois deste estudo é de um sujeito de aproximadamente 30 anos, que, ao ler o livro, o fechou, ficou parado por um tempo. Em seguida, olhou para o chão, olhou para os olhos da pesquisadora e falou: Olhar dois: "Meu pai nunca brincou comigo. Eu brinco muito com meus filhos... esse livro me fez pensar sobre isso. Sinto falta de ser criança com meu pai”. Nesse pequeno trecho, percebemos que sentimentos nascem da relação com as formas e as imagens que o livro apresenta. Esse arrebatamento, o prazer estético ou deslocamento dos sentidos, "[...] reside na vivência da harmonia descoberta entre as formas dinâmicas dos sentimentos e as formas da arte (ou dos objetos estéticos)" (DUARTE JR., 1981, p. 85).

$\mathrm{Na}$ obra de Lugones e Rampazo (2017), as formas e os pequenos textos funcionam como dispositivo provocador da experiência estética, pois os " [...] sentimentos descobrem-se nas formas que lhes são dadas, como eu me descubro no espelho. Através dos sentimentos identificamo-nos com o objeto estético, e com ele nos tornamos um" (DUARTE JR., 1981, p. $85)$.

O olhar três foi coletado por uma mãe (professora de arte) que definiu o livro como uma delicada metáfora da vida, permitindo aberturas para questionamentos em torno das relações existentes entre vida e arte. A criança de 9 anos estava à espera de sua irmã, na saída da escola. Ela leu o livro, parou em algumas páginas, fechou e ficou em silêncio olhando para o horizonte. A mãe então perguntou o que a criança tinha achado, e ela respondeu: Olhar três: "Lembrei do seu pai". (Não conheceu o avô e em casa retomou o assunto). "Sabe o livro do Pablo? Lembrei do vô Silvio. Fiquei olhando aquela página escura. Eu olhei, olhei e pensei, porque Deus tinha de levar ele?! Mas ele foi. É a vida dele. Eu queria ter conhecido ele".

Nesse trecho do olhar três (de uma criança), evidenciamos a potência da obra literária como disparadora da sensação, da reflexão e do pensamento. Nesse sentido, temos uma obra que se apoia na imagem que transcende o texto, composto por palavras e frases que agem na dimensão da metáfora, evidenciando a força da obra na provocação de momentos de fruição estética. O olhar três destaca que as páginas escuras (tons de azul escuro e pontilhados luminosos denotando a noite) representam a partida ou a morte de alguém, nesse caso o pai da criança. Ela, que leu o livro, lembrou ou se relacionou com a morte de alguém que sequer conheceu, mas sente a presença, ou a ausência, em uma relação viva entre arte e vida.

O olhar quatro recebeu o livro, parou o que estava a fazer e apreciou com cuidado cada página da obra. Ao final, falou: 


\title{
Linguagens - Revista de Letras, Artes e Comunicação - ISSN 1981- 9943 \\ Blumenau, v. 13, n. 3, p. 412-429, set./dez. 2019 \\ DOI: http://dx.doi.org/10.7867/1981-9943.2019v13n3p412-429
}

\begin{abstract}
Olhar quatro: "Preciso me recompor, isso tocou-me muito, muito. Desculpe, as lágrimas vieram porque lembre de meu ex-marido. Nesse final de semana, minha filha ainda falava dele pra mim, e foi tão forte ela dizer que ele está ficando velhinho e ela tem saudade dele com vitalidade. Lembrei dele plantando no nosso jardim com ela, ensinando a andar de bicicleta, correndo na praia, nossa ele é um super paizão. Me deu uma dor, uma dor de imaginar que um dia ele vai e minha filha vai sentir a ausência dele, que estamos ficando velhos".
\end{abstract}

Depois dessa declaração, podemos afirmar a potência desse livro para pensar na vida, como metáfora para a vida, para a possibilidade de adultos e crianças perceberem suas sensações e trazerem à tona suas histórias e condições existenciais. Por minutos, a obra habita a subjetividade dos sujeitos revelando a potência das imagens e das palavras.

Nesses excertos, percebemos que a relação entre familiares aparece com intensidade, sendo um aspecto que o livro despertou nos quatro observadores. Eles expuseram memórias de experiências de relações que envolvem pais e filhos. Esse indício mostra que a obra possui força para despertar, por meio de sua narrativa, a substância que nos torna humanos, a sensibilidade que desestabiliza a letargia dos corpos anestesiados pela nossa época.

Esse fato aponta para reflexões em torno do lugar da obra de arte em tempos de censura camuflada de moralismo, de modo que o livro literário analisado neste estudo, que a princípio foi criado para ser apreciado pelo público infantil, pode ser apreciado por qualquer "[...] tipo de leitor que deseja lidar com o livro e descobrir as particularidades deste universo" (CARVALHO, 2008, p. 114).

Se a arte possui potencialidades para evocar a substância que nos torna humanos, podemos compreender os motivos pelos quais, em nosso tempo, alguns movimentos querem tentar coibir a manifestação da livre expressão artística. Desse modo, se a arte possui potência para intensificar aspectos da estrutura cognitiva e sensível, a obra de arte literária possui força humanizadora, pois afeta diretamente a dimensão da percepção sensorial.

Essas reflexões permitem salientar a importância da educação e do desenvolvimento dos sentidos de modo que possamos, de forma significativa, consciente, nos tornar sensíveis. Essa sensibilidade colocar-nos-ia presentes ao que nos acontece; em consequência disso, obteríamos reflexões cada vez mais valiosas, bem como aguçaria nossas capacidades perceptivas (DUARTE JR., 2001). A potência do objeto artístico possibilita compreender que a experiência estética ocorre na relação com a obra, que os afetos que emanam da arte também se originam em contextos culturais, históricos e subjetivos onde o criador está inserido, fazendo do livro literário um “[...] objeto carregado de significações humanas" (CARVALHO, 2008, p. 104). 


\section{Linguagens - Revista de Letras, Artes e Comunicação - ISSN 1981- 9943 \\ Blumenau, v. 13, n. 3, p. 412-429, set./dez. 2019 \\ DOI: http://dx.doi.org/10.7867/1981-9943.2019v13n3p412-429}

Por necessitar de certa inteligência humana, além da racionalidade abstrata, que o criador de arte recorre a uma certa compreensão ampliada e sensível para desenvolver uma ideia, permitindo que o resultado também seja potente ao ponto de sermos provocados a apreender "[...] o signo estético com o corpo inteiro, e não apenas com a razão conceitual" (DUARTE JR., 2001, p. 23).

Por fim, destacamos que a literatura consiste em um poderoso instrumento para a educação da sensibilidade, de modo que pode ampliar progressivamente os sentidos, bem como a percepção das realidades e contextos vivenciados (DUARTE JR., 2001). Essas constatações esclarecem o lugar da arte no cotidiano e na vida.

\section{ARGUMENTOS FINAIS}

Figura 3. Páginas finais do livro

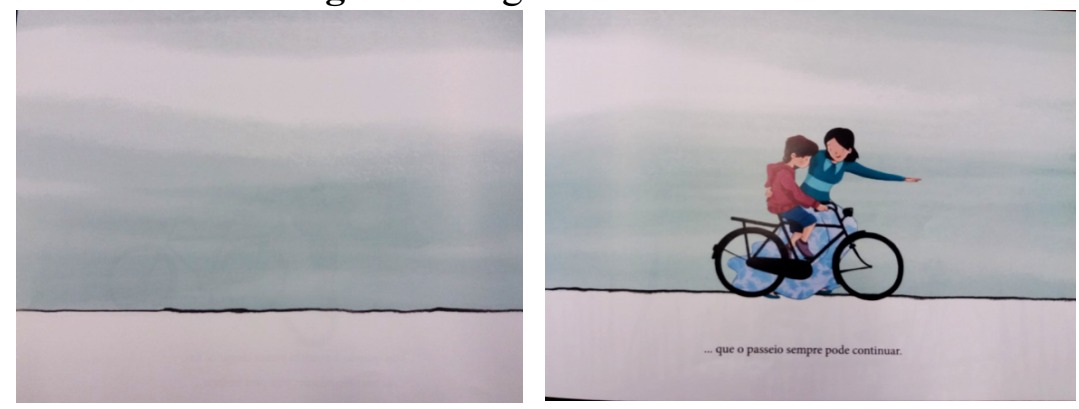

Fonte: Extraídas de O passeio, Lugones e Rampazo (2017, p. 45-46).

As imagens que abrem esses argumentos finais nos incitam a continuar o passeio, a continuar o caminho, com quem estiver ao nosso lado. Aqui, como metáfora da vida, da estética e, em especial, da relação com a arte... continuar em processo de fruição.

Ao tecer nossas reflexões que findam ou instigam a outros percursos investigativos, percebemos que o livro de literatura provoca experiências de ordem estética, aciona mecanismos da sensibilidade humana. A experiência que é estética abarca o corpo como um todo, as sensações decorrentes dos sentidos, em um jogo instantâneo e integrado com o pensamento. Nesse caso, ousamos afirmar que o pensamento é corpo e que o corpo é pensamento. Ou seja, não é possível apartar o que ocorre em nosso cérebro do que ocorre em nossos órgãos sensíveis e no corpo como um todo.

O livro de literatura pode desafiar os valores contemporâneos que ainda valorizam um modo de pensamento pautado no racionalismo, desconectado da dimensão sensível do ser humano e os saberes que advém do corpo sensível. A obra de Lugones e Rampazo (2017) age diretamente em nossa carne e sensibilidades corporais, desencadeando a experiência do belo 


\section{Linguagens - Revista de Letras, Artes e Comunicação - ISSN 1981- 9943 \\ Blumenau, v. 13, n. 3, p. 412-429, set./dez. 2019 \\ DOI: http://dx.doi.org/10.7867/1981-9943.2019v13n3p412-429}

que afeta a potência do ser e de estar no mundo (DUARTE JR., 2001). Essa experiência do belo está intimamente conectada à inquietude causada pelo prazer da experiência estética e de nossos sentidos, permitindo o que o autor afirma ser "aisthesis", ou estesia. Ela nos remete aos saberes advindos da sensibilidade, que elaboramos ao experienciar a obra de arte.

Em suma, essa obra de arte literária oferece elementos para que a experiência estética aconteça, principalmente se considerarmos que a experiência estética possui força para mobilizar um corpo embrutecido pelos mecanismos de controle que a época atual apresenta. A principal substância da obra de arte, condensada em signos que traduzem a subjetividade do criador, é, assim, a própria condição humana e existencial tornada em arte.

A obra de Lugones e Rampazo (2017) apresenta elementos simbólicos que afetam o observador a tal ponto que o desloca de seu lugar comum, permanecendo como marca que "arrepia", que evoca lembranças da relação entre pais e filhos e toda a emoção subjetiva que as memórias podem trazer à tona.

O livro abre brechas no tempo e no espaço, de modo que a sensibilidade possa aflorar em uma percepção da dimensão dos sentidos e os saberes que provém dessa fonte complexa e inerente ao ser humano. A obra permite a contemplação da vida em uma dimensão que traz à tona a humanidade, aparentemente adormecida, mas que posta em jogo de contemplação, fruição e experiência estética, desperta nossas capacidades sensíveis.

A metáfora da vida contida na obra de Lugones e Rampazo (2017) abre caminhos para que a experiência estética significativa nos aconteça - aquela que exige uma ação que interrompa o fluxo dos excessos da vida atual e estabeleça paradas. Uma parada para a fluência desinteressada do pensamento, para a percepção ser aguçada e os sentidos dilatados potencialmente para que possamos cultivar a potência da fruição.

Se a arte é composta de matéria puramente humana, que essa matéria possa encontrar consonâncias com outra substância puramente humana que se configura nas dinâmicas do corpo. A obra de arte literária estabelece diálogos subversivos com o observador e desafia condicionamentos em tempos de iminente censura do óbvio. Se a Arte é sensação, composta de signos do sentimento humano, está prenhe de possibilidades sensíveis.

\section{REFERÊNCIAS}

BARTHES, Roland. O prazer do texto. Tradução J. Guinsburg. 4. ed. São Paulo. Perspectiva, 1996. 
CARVALHO, Carla. Relação das professoras e professores com a arte por meio do livro de arte para criança na rede municipal de ensino de Blumenau - SC. 2008. $313 \mathrm{f}$. Tese (Doutorado em Educação) - Universidade Federal do Paraná, Curitiba, 2008.

CARVALHO, Caroline. Literatura fruitiva e a formação de leitores: estudos acerca da educação estética. In: NEITZEL, Adair de Aguiar; CARVALHO, Carla. (Orgs.). Formação estética e artística: saberes sensíveis. Curitiba, PR: CRV, 2012. p. 55-69.

DELEUZE, Gilles; GUATTARI, Félix. O que é Filosofia. São Paulo: 34, 1992.

DINIZ, Ligia G. Uma alma que dança ou despenca: corpo e presença na experiência literária. Revista Brasileira de Estudos da Presença, Porto Alegre, v. 7, n. 3, p. 477-504, set./dez. 2017. DOI: http://dx.doi.org/10.1590/2237-266068773

DUARTE JR., João Francisco. Entrevista com João Francisco Duarte Júnior. Revista Contrapontos (online), Itajaí, v. 12, n. 3, p. 362-367, set./dez. 2012. DOI: http://dx.doi.org/10.14210/contrapontos.v12n3.p362-367

DUARTE JR., João Francisco. Fundamentos estéticos da educação. São Paulo. Cortez: Autores associados. 1981.

DUARTE JR., João Francisco. O sentido dos sentidos: a educação (do) sensível. Curitiba. Criar Edições, 2001.

LARROSA, Jorge. Tremores: escritos sobre experiência. Tradução Cristina Antunes e João Wanderley Geraldi. Belo Horizonte: Autêntica, 2016.

LUGONES, Pablo; RAMPAZO, Alexandre. O passeio. Blumenau: Gato Leitor, 2017.

NEITZEL, Adair de Aguiar; BRIDON, Janete. Literatura no ensino médio: percepções dos estudantes acerca da poesia em meio eletrônico. In: NEITZEL, Adair de Aguiar; CARVALHO, Carla. (Orgs.). Formação estética e artística: saberes sensíveis. Curitiba, PR: CRV, 2012. p. 71-89. 